\title{
Correspondence
}

\section{Defeating the Defeat Depression Campaign}

Sir: The recent Defeat Depression Campaign is an excellent example of preventive medicine at its best, for which the Royal College of Psychiatrists and the Royal College of General Practitioners should take full credit. Why then is the Department of Health seeking to undermine this campaign, for this is surely what it will achieve with its recent guidelines to NHS occupational physicians advising on the suitability for employment of someone with a past history of depression. These guidelines have arisen out of the Beverly Allitt affair.

Recently I learnt that a woman applied to work as a Macmillan nurse assistant at a nearby hospital. She has a past history of post natal depression, treated successfully as an outpatient and she made a full and normal recovery. She is not on any current medication. She was successful at interview, and her appointment was confirmed subject to a medical examination. At this she was told that it was Department of Health policy that people with a significant past psychiatric history cannot be employed in direct patient contact in the NHS. She was offered the alternative of applying for a different type of post.

There is clearly something seriously wrong here. Nor is this the first instance that I have come across whereby people with a psychiatric history have been penalized for it. The recent Department of Health initiative on supervision registers smacks of 'big brother' and social control. The point is that these policies will directly add to the stigma of mental illness and serve only to drive it further underground. Patients will be even less keen to admit to their suffering, and most of the good work achieved by the Defeat Depression Campaign will be lost. It is worth remembering that the NHS is the single biggest employer in the country. It is not going to help those with a history of depression to find themselves excluded automatically from working in the organisation. Moreover, other employers may follow the NHS' example, compounding matters.

It is time that the Department of Health showed an example, and acted to reduce the stigma of depression, not increase it. Our college should insist that it does so.

G.E.P VINCENT, Friarage Hospital, Northallerton, North Yorkshire DL6 1JG

\section{High dose antipsychotic medication}

Sir: There has been much recent interest in the dosage limits given in the British National Formulary (BNF, 1994) for high dose antipsychotic medication and the Consensus Statement of the Royal College of Psychiatrists (1993) has recently been published. One of its recommendations is that trainee psychiatrists should not take the decision to exceed BNF limits.

The Consensus Statement focuses mainly on maximum daily dosage during regular administration. However, the BNF recommendations for acute dosing may contain surprises for many clinicians. For example, the starting dose for chlorpromazine, even in acute psychoses, of $25 \mathrm{mg}$ tds appears extremely low compared with that generally used. Few very disturbed patients are likely to respond to only $50 \mathrm{mg}$ chlorpromazine intramuscularly, repeated at a maximum interval of six hours. Dollery (1991) suggested up to $100 \mathrm{mg}$ intramuscularly every four hours in acute schizophrenia.

The BNF gives dose equivalents for a number of drugs, although since these drugs act on a wide range of receptors, equivalence for dopamine blockade may not be equivalence for sedation or tranquillisation. In terms of dose equivalents, much greater antipsychotic potency within BNF limits is possible by using drugs other than chlorpromazine. From the dosage viewpoint, in the acute situation, haloperidol would appear the drug of choice, since it has the greatest flexibility of dosage both orally and intramuscularly. For oral use, thioridazine can be given in much larger equivalent dosage (300 $\mathrm{mg}$ bd) than chlorpromazine. However, there is no good evidence that thioridazine and haloperidol are safer to use than chlorpromazine.

I would like to suggest that the BNF limits for initiating therapy with antipsychotics appear inconsistent and it is not clear that there limits have any pharmacological or toxicological basis. However, these limits have considerable medicolegal significance since they are generally based on the terms of the manufacturer's product licence. There is clearly an urgent need for reappraisal of appropriate dosage regimes to be used for initiation of acute therapy with antipsychotic drugs in clinical practice.

BNF (1994) British National Formulary, Number 27. London: British Medical Association and Royal Pharmaceutical Society of Great Britain.

DOLLEY, C. (1991) In Therapeutic Drugs. London: Churchill Livingstone. 
ROYAl COLlEge OF PSYChIATRISTS (1993) Councl Report CR26: Consensus Statement on the Use of High Dose Antipsychotic Medication. London: Royal College of Psychiatrists.

PAUL Boston, Department of Psychiatry, Faculty of Medicine, University of Leicester LE2 7LX

Sir: We welcome the recent Consensus Statement on the Use of High Dose Antipsychotic Medication (Thompson, 1994) but would welcome further guidance on the use of high dosages, particularly when polypharmacy is involved.

The consensus statement provides clear guidance for the use of single medications at dosages exceeding the advisory limit for general use and in its Guidelines and Suggestions indicates that a combined dosage of more than one antipsychotic should not exceed the recommended upper limit. However no guidance is given as to how to calculate the maximum daily dosage when using two or more drugs. The difficulties in estimation of maximum dosages when using polypharmacy are exacerbated by the lack of a single scheme of "chlorpromazine equivalents". There is also a lack of consensus amongst the values given by the manufacturers and in the literature (Foster, 1989).

Relatively modest dosages of two antipsychotics may lead to dosage levels which if expressed in chlorpromazine equivalents far exceed the recommended dally dosage for one medication. However the simultaneous prescription of more than one antipsychotic occurs regularly in routine clinical practice without the rigorous safeguards and precautions laid out in the consensus statement.

It is unlikely that the pharmaceutical industry would wish to take the lead in the production of guidelines for use when polypharmacy is indicated. We would thus urge the College to encourage and facilitate further work in this important area.

FOSTER, P. (1989) Neuroleptic equivalence. The Pharmaceutical Journal, 243, 431-432

THOMPSON, C. (1994) The use of high-dose antipsychotic medication. Brtish Journal of Psychiatry, 164, 448-458

A. Valmana and M. POTter, Springfield Hospital, 61 Glenburnie Road, London SW17

\section{Registrar's note}

The letters from Dr P. Boston and Dr A. Valmana \& Dr M. Potter indicate that there is still much detailed work to be done following the well accepted but broadly defined consensus statement on high dose antipsychotic medication. These and other letters have been referred to the psychopharmacology group of the College for consideration.
The detail of four hourly or six hourly starting doses of antipsychotics either intramuscular or oral were not considered by the group. They are only relevant to the consensus statement when the total daily dose exceeds the daily BNF limit in which circumstances the group considered that it would be necessary for the dosing schedule to be seen and approved by a more senior psychiatrist, i.e. a psychiatrist with Membership of the Royal College of Psychiatrists. It is nevertheless an important point that dangers can arise in acute dosing schedules without the BNF dose being exceeded, and regardless of the general safety of neuroleptic agents, psychiatrists of all grades need to be constantly vigilant to motor and autonomic side effects.

\section{THOMPSON, Registrar, Royal College of Psychiatrists}

\section{The College's ethnic monitoring exercise}

Sir: A circular from the Registrar states that our College is trying to eliminate discrimination on ethnic grounds in psychiatric practice and in the College's own activities. Having stated that a record of the ethnic origin of its members would help the College in this endeavour, he asks for information about country of birth and racial designation.

Only a person who has never experienced the disbelief, anger and distress inseparable from racial discrimination will fail to see how illadvised, even dangerous, this undoubtedly wellintentioned exercise actually is. First, it calls upon members to think of themselves in racial terms which is counter to the effort to promote non-racial thinking. Those who are able to think non-racially will find the requirement disconcerting. Second, it calls upon non-white members whose 'British' or 'European'-type names have so far enabled them to slip past the short-listing obstacle to identify themselves by race, and perhaps alert people of ill-will on short-listing panels and Advisory Appointments Committees of their racial origins. Third, how would a record of ethnic origins help in eliminating discrimination in psychiatric practice? If the College is not contemplating assigning patients to therapists by race, where lies the logic in this? Finally, since discrimination enjoys the statutory support of such instruments as Achieving $A$ Balance, how does our College propose to get past Statesponsored racial discrimination?

If we wish to make a beginning in reducing discrimination in College activities, all that is required is for the College to insist on merit as the only criterion for access to training and employment opportunities. 